\title{
Mastery and self-esteem mediate the association between visual acuity and mental health: a population-based longitudinal cohort study
}

I. M. Maaswinkel ${ }^{1 \dagger}$, H. P. A. van der Aa ${ }^{1 *+}$, G. H. M. B. van Rens ${ }^{1,2}$, A. T. F. Beekmann ${ }^{3,4}$, J. W. R. Twisk ${ }^{5}$ and R. M. A. van Nispen ${ }^{1}$

\begin{abstract}
Background: With deteriorating eyesight, people often become dependent on others for many aspects of their daily lives. As a result, they feel less 'in control' and experience lower self-esteem. Lower sense of mastery and selfesteem are known to predict depression, but their roles in people with visual impairment have only marginally been investigated. Therefore, this study aimed to determine the influence of mastery and self-esteem on the relationship between visual acuity and mental health.

Methods: A longitudinal cohort study was performed using data from the Longitudinal Aging Study Amsterdam (LASA), collected between 2001 and 2012. A community-based population of 2599 older adults were included, who were randomly selected from population registers. Outcomes of interest were the Pearlin Mastery Scale, Rosenberg Self-Esteem Scale, Center for Epidemiologic Studies - Depression scale and the Hospital Anxiety Depression Scale Anxiety subscale. Linear mixed models were used to establish the association between visual acuity and mental health over time.

Results: Mean age was 72 years, $56 \%$ was female and $1.2 \%$ qualified as having low vision. Visual impairment was associated with a lower sense of mastery $(\beta=-0.477, p<0.001)$, lower self-esteem $(\beta=-0.166, p=0.008)$ and more depression $(\beta=0.235, p<0.001$ ). No significant association between visual acuity and anxiety was found. The relationship between visual acuity and depression was mediated by self-esteem (25\%) and sense of mastery (79\%).

Conclusions: Vision loss was associated with depression. This association was mediated by self-esteem and sense of mastery. This provides us with new possibilities to identify, support and treat those at risk for developing depression by aiming to increase their self-esteem and sense of mastery.
\end{abstract}

Keywords: Vision loss, Visual acuity, Depression, Anxiety, Mastery, Self-esteem, Longitudinal cohort

\footnotetext{
* Correspondence: h.vanderaa@amsterdamumc.nl

${ }^{\dagger}$. M. Maaswinkel and H. P. A. van der Aa contributed equally to this work.

'Amsterdam UMC, Vrije Universiteit Amsterdam, Ophthalmology, Amsterdam

Public Health Research Institute, Amsterdam, The Netherlands

Full list of author information is available at the end of the article
}

(c) The Author(s). 2020 Open Access This article is licensed under a Creative Commons Attribution 4.0 International License, which permits use, sharing, adaptation, distribution and reproduction in any medium or format, as long as you give appropriate credit to the original author(s) and the source, provide a link to the Creative Commons licence, and indicate if changes were made. The images or other third party material in this article are included in the article's Creative Commons licence, unless indicated otherwise in a credit line to the material. If material is not included in the article's Creative Commons licence and your intended use is not permitted by statutory regulation or exceeds the permitted use, you will need to obtain permission directly from the copyright holder. To view a copy of this licence, visit http://creativecommons.org/licenses/by/4.0/. The Creative Commons Public Domain Dedication waiver (http://creativecommons.org/publicdomain/zero/1.0/) applies to the data made available in this article, unless otherwise stated in a credit line to the data. 


\section{Background}

Globally, about 285 to 440 million people suffer from visual impairment, mostly due to uncorrected refractive errors and cataract $[1,2]$. Increasing life expectancy rates in high-income countries [3] are expected to dramatically raise the prevalence of visual impairment and subsequent need for eye-care services and associated health care costs for years to come [4]. Global health is also greatly impacted by mental health issues [5], especially in older adults [6] and in those with visual impairment [7-11]. The prevalence of depression in older adults with visual impairment is estimated to approximate a staggering $30 \%$, compared to roughly $11 \%$ in control groups [12, 13]. And with an estimated prevalence of $15 \%$, anxiety symptoms are twice as common in older adults with visual impairment than those without visual impairment [14].

Different mechanisms have been proposed to explain the association between visual impairment and mental health [15]. The severity of vision loss and coherent loss of functional capacity partly explain the association between visual impairment and mental health [16-20]. Social factors, i.e. supporting network size and social support, also seem to have an influence $[11,21]$. However, many studies indicate that intrapersonal factors play a significant role in the psychological outcomes of vision loss $[19,22]$. For instance, greater acceptance of vision loss seems to be an important predictor of improved mental health [19, 23-26]. In addition, problem solving skills [27], control strategies [28], (mal) adaptive coping strategies [22, 24], and a person's perceived selfefficacy to use coping strategies [29] seem to largely influence mental health in people with vision impairment.

Two important intrapersonal factors, however, have not or only marginally been considered in previous studies. The first is mastery, which has been defined as the extent to which someone feels in control over his/her life and environment [30]. Several studies have shown positive associations of mastery with adaptation to stressful life situations and increased physical and mental health $[31,32]$. As our society relies heavily on visual functioning, those with visual disabilities often experience a loss of control and dependency on others [3335]. This experience of an 'external locus of control' [36] may be a major factor in the development of depressive symptoms in this population. The second factor is selfesteem, which has been defined as the way someone evaluates or appraises their own self-worth, and which is influenced by interactions with (significant) others [37]. Limitations in activities of daily living due to visual impairment, having to rely on others and facing negative attitudes towards visual disability, may largely influence a person's self-esteem [35], which may increase their risk of mental health problems [38]. In a cross-sectional study, Kurtović et al. found that self-esteem was associated with depression in adults with visual impairment [21]. Besides optimism and social support, they emphasize the importance of focusing on self-esteem in rehabilitation practice to increase mental health in people with visual disability.

Because problems with mastery and self-esteem seem to increase after (completely or partially) losing vision [35], we propose that the relationship between vision loss and mental health is mediated by these intrapersonal factors. We hypothesise that visual impairment has a negative impact on mental health through a reduced sense of mastery and self-esteem. We aim to investigate this hypothesis in a large sample of older adults who were followed over time, which could provide us with greater insight into mental health in people with visual impairment, and help us determine new and better ways to address this problem.

\section{Methods \\ Study design}

A longitudinal cohort study was performed, using data from four time points from the Longitudinal Aging Study Amsterdam (LASA) [39], collected from 2001 through 2012. In this period, participants were measured four times; in 2001-2002 (cycle E), in 2005-2006 (cycle F), in 2008-2009 (cycle G) and in 2011-2012 (cycle H). While LASA has been collecting data since 1992, we only included these cycles because visual acuity was only measured at these time points.

\section{Participants}

LASA's first cohort was formed in 1992 from a random sample of people aged 55 to 85 years, drawn from population registers in 11 municipalities in the Netherlands. The acquired sample was stratified for age, gender and level of urbanisation. This sample was first used in the NESTOR study on Living Arrangements and Social Networks (LSN) [40]. In 2002-2003, a second cohort was formed from an identical sampling frame. This process has shaped representative samples of the older Dutch population and has further been described in detail in previous publications [41-43]. In total, data were collected on 2599 unique participants. Selection bias was kept to a minimum by including a very large population, by recruiting participants from three culturally distinct areas with different levels of urbanisation and by contacting members of a general population rather than clinical recruitment [44].

\section{Outcome measures \\ Visual acuity}

Visual acuity was reported in terms of visual acuity rating (VAR), measured using a Colenbrander 1-m chart 
with $a+1.00$ dioptre magnifying glass [45]. For analysis, all obtained VAR scores were converted to $\log$ units (logarithm of the Minimal Angle of Resolution, logMAR) [46]. Visual acuity of the better eye was used for analysis, regardless of lateralisation.

\section{Mental health}

Validated Dutch translations of widely-used questionnaires were deployed to assess different aspects of mental health. For depressive symptoms, the Center for Epidemiologic Studies - Depression scale (CES-D) [47] was used. The CES-D questionnaire contains 20 items, measuring depressive symptoms on a 4-point Likert scale (scored 0-3). For symptoms of anxiety, the Hospital Anxiety and Depression Scale - Anxiety Subscale (HADS-A) [48] was used. The HADS-A contains 7 items, measuring symptoms of anxiety on a 4-point Likert scale (scored 0-3). For mastery, the Pearlin Mastery Scale (PMS) [30] was used. The PMS questionnaire contains 7 items, measuring mastery on a 5-point Likert scale (scored 0-4). For self-esteem, the Rosenberg SelfEsteem Scale (RSES) [49] was used. The RSES questionnaire contains 10 items, of which the first 4 were included, measuring self-esteem on a 5-point Likert scale (scored 0-4). Items using adverse wording were coded reversely. Thus, higher scores corresponded with greater levels of depression, anxiety, mastery and self-esteem, respectively.

\section{Other variables}

Additionally, other variables were obtained, including age, education, nationality, living arrangement (independent or not), marital status (currently married or not), partner status (partner being present or not), personal network size, functional limitations (i.e. dressing and undressing, chair use, clipping one's toenails, walking, transportation and stair use), special housing adjustments (none or one and more) and chronic somatic comorbid diseases (i.e. chronic non-specific lung disease, cardiac disease, peripheral artery disease, stroke, diabetes mellitus, arthritis and malignancies). These variables were chosen either to describe essential characteristics of the research population, or because previous literature showed them to be factors of importance in the studied associations. During statistical analysis, age was found to grossly violate the linearity assumption, rendering the variable unfit to be included as a continuous measure. Therefore, age was divided into three groups to facilitate separate analysis for three clinically relevant groups: 1 ) a working-age population (up to 65 years old in the Netherlands), 2) a middle old population (65 to 90 years old) and 3) the oldest old (90 years and older). For the oldest old we chose a cut-off of 90 years and older since this is the fastest growing segment of the Dutch population and this age group constitutes a growing and distinct group of patients with visual impairment [50]. To address the possible issue of information bias, data collection on outcomes occurred in a highly structured fashion and similarly for all participants.

\section{Statistical analyses \\ Data preparation}

IRT-analyses - also called latent trait analyses - were performed on the questionnaires at all measurement time-points to estimate individual latent trait $(\theta-)$ scores per item. These statistical models incorporate the characteristics of questionnaire items and all obtained responses, rendering a more accurate representation of the respondent's score on the latent construct, which was originally set out to be measured. Item-response models provide certain compelling advantages, describing the relationship between a latent trait, the characteristics of the items in the scale and the answers of respondents to the individual items [51]. This results in a more accurate estimation of one's true latent trait (e.g. level of depression), increasing the validity of the used questionnaires and the accuracy of the obtained results. A Graded Response Model (GRM) was chosen as the preferred IRTmodel for its flexibility regarding item goodness-of-fit [52]. In order for IRT-analyses to be accurate, questionnaires should meet the criteria for three crucial assumptions; unidimensionality, local independence of items and monotonicity [53]. Unidimensionality was tested using standard indices. Local independence of items and monotonicity were checked by analysing residual covariance and plotting results of Mokken analyses, respectively [54]. Confirmatory Factor Analysis (CFA) was conducted to assess goodness-of-fit and the estimated number of fundamental factors in the model. Based upon the retrieved parameters, the acquired $\theta$ (ranging from -4.0 to +4.0 ) was used in further analysis. Data preparation was conducted in RStudio, Version 0.99.896.

\section{Primary analyses}

Linear mixed modelling (LMM) with maximum likelihood estimation was used to estimate the associations between $\log$ MAR visual acuity and mastery, self-esteem, depression and anxiety. LMM is a preferred statistical method for analysing longitudinal data, using random intercepts and fixed variables. This particular model was chosen for its superior properties in dealing with missing values - which were inherent to the design of the study - and its integration of both interpersonal and intrapersonal variance [55]. Possible confounding [44] was analysed and adjusted for. Analyses were carried out using $\log$ MAR visual acuity as a continuous independent measure for visual impairment. IBM SPSS Statistics, Version 22.0 was used to conduct the analyses. 


\section{Mediation analyses}

We hypothesise that mastery and self-esteem mediate the effect between visual acuity (the independent variable) and depression and anxiety (dependent variables) over time. First, an LMM with maximum likelihood estimation was performed to describe the total effect of the independent variable on the dependent variables. Second, LMM analysis was performed to calculate the 'a-path'; the association between the independent variable and the potential mediators. Third, a final LMM with maximum likelihood estimation was performed to estimate the direct effect (c') of the independent variable on the dependent variables, whilst controlling for the potential mediators (b), by including it in the model. Subsequently, these three pathways were compared. Again, potential confounding was analysed and adjusted for.

\section{Results}

\section{Participant characteristics}

Data pertaining to participant inclusion, follow-up rates and attrition was retrieved from previous LASA publications (see Fig. 1) [39]. Our study only included data that were collected between 2001 and 2012 (cycles E to H) because visual acuity was measured at these time points. Several participants dropped out during the course of the study because they died, were ineligible to participate, no longer wanted to participate or could not be contacted. Participants were deemed ineligible when they no longer met the initial inclusion criteria [56]. Due to this loss to follow-up and the inclusion of participants at various moments in time, the mean follow-up time was 5.9 years with a standard error of 0.07 years This was calculated using the difference between age at first measurement and age at last measurement for each participant. A baseline summary containing data extracted

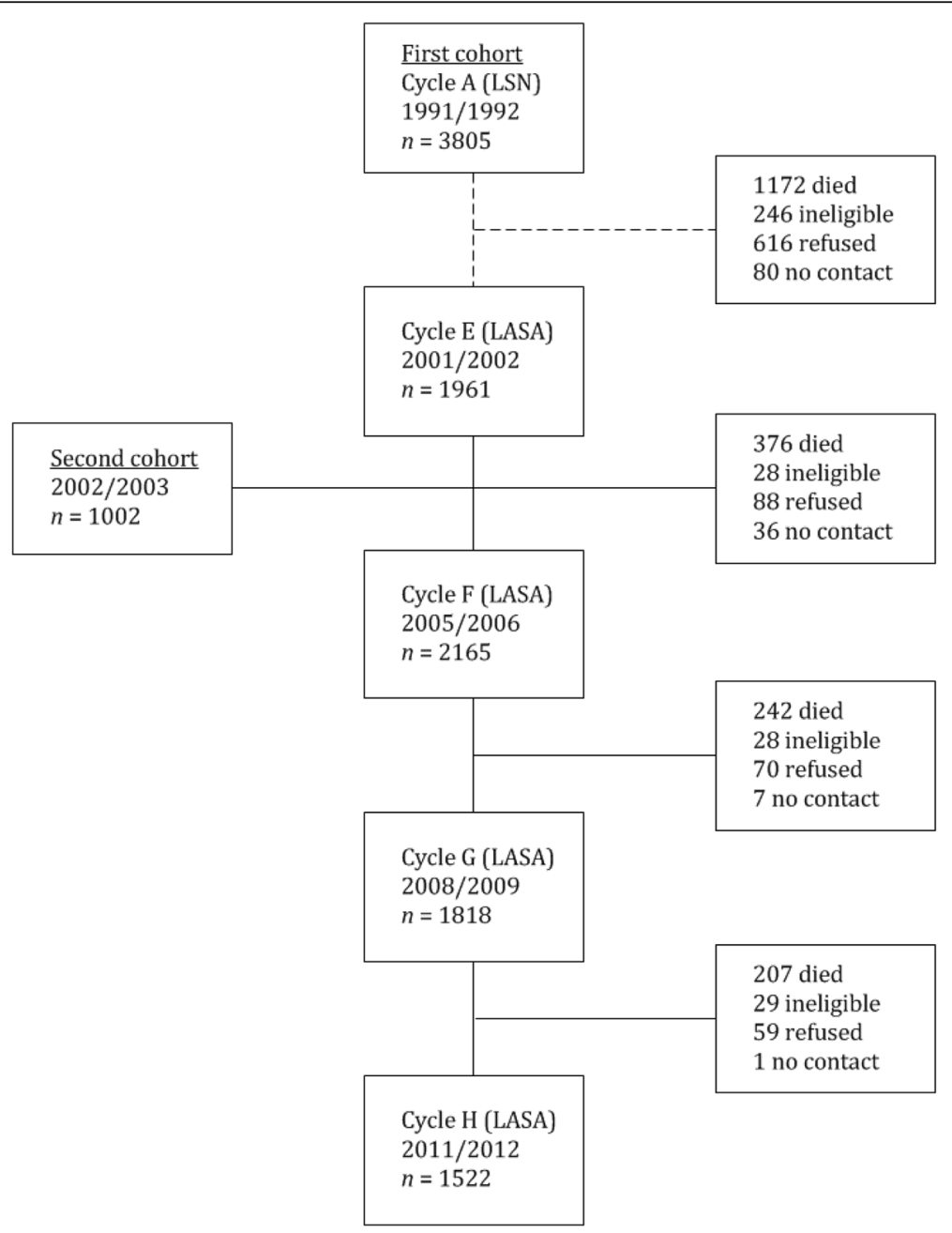

Fig. 1 Inclusion, loss to follow up and attrition per measurement 
Table 1 Patient characteristics at baseline (total $n=2599$ of which $n=1961$ for cycle $\mathrm{E}$ and $n=638$ for cycle F)

\begin{tabular}{|c|c|}
\hline Independent variables & \\
\hline Visual acuity (logMAR), mean (SE) & $0.08(0.003)$ \\
\hline \multicolumn{2}{|l|}{ Visual Groupt } \\
\hline No visual impairment, $N(\%)$ & $2020(78 \%)$ \\
\hline Low vision, $N(\%)$ & $32(1,2 \%)$ \\
\hline Missing, $N(\%)$ & $547(21 \%)$ \\
\hline \multicolumn{2}{|l|}{ Dependent variables $\not$} \\
\hline Depression $(\theta)$, mean $(\mathrm{SE})$ & $0.0044(0.0186)$ \\
\hline Anxiety $(\theta)$, mean (SE) & $0.086(0.0170)$ \\
\hline Mastery $(\theta)$, mean (SE) & $0.046(0.0192)$ \\
\hline Self-esteem $(\theta)$, mean (SE) & $-0.00122(0.0186)$ \\
\hline \multicolumn{2}{|l|}{ Other variables } \\
\hline Age, mean (SE) & $72(0.181)$ \\
\hline \multicolumn{2}{|l|}{ Age Group } \\
\hline Up to 65 years, $N(\%)$ & $682(26.2 \%)$ \\
\hline 65 to 90 years, $N(\%)$ & $1814(70 \%)$ \\
\hline 90 years and up, $N(\%)$ & $103(4.0 \%)$ \\
\hline Female gender, $N(\%)$ & $1457(56 \%)$ \\
\hline Living independently, $N(\%)$ & $2251(87 \%)$ \\
\hline Currently married, $N(\%)$ & $1573(61 \%)$ \\
\hline Dutch nationality, N (\%) & $2585(99 \%)$ \\
\hline Network size, mean (SE; range) & $16.1(0.200 ; 0-67)$ \\
\hline \multicolumn{2}{|l|}{ Number of chronic somatic disorders } \\
\hline None, $N(\%)$ & $650(25 \%)$ \\
\hline One, N (\%) & $892(34 \%)$ \\
\hline Two or more, $N(\%)$ & $783(30 \%)$ \\
\hline Missing, $N(\%)$ & $274(11 \%)$ \\
\hline No functional limitations, $N(\%)$ & $1075(41 \%)$ \\
\hline Having a partner, $N(\%)$ & $1683(65 \%)$ \\
\hline No special housing adjustments, N (\%) & 1709 (66\%) \\
\hline
\end{tabular}

† Low vision was defined as logMAR visual acuity of 0.50 and higher * Factor scores (range: -4.0 to 4.0 ), representing latent trait scores, acquired by Item Response Theory (IRT-)analysis on the used questionnaires - for depression; CES-D (Center for Epidemiologic Studies - Depression Scale) [29], HADS-A (Hospital Anxiety and Depression Scale - Anxiety Subscale) [30], PMS-5 (5-item Pearlin Mastery Scale) [31] and RSES (Rosenberg Self-Esteem Scale) [32]

from participants' first available measurement $(n=2599$ in total, of which $n=1961$ for cycle E and $n=638$ for cycle F), is available in Table 1 . Mean age was 72 years, $56 \%$ was female, almost all had the Dutch nationality, $72 \%$ had one or more chronic somatic diseases and $1.2 \%$ qualified as having low vision.

\section{Data preparation}

IRT-analyses were performed on the questionnaires for depression, anxiety, mastery and self-esteem at all four measurement time-points to estimate individual latent trait $(\theta-)$ scores per item. The preferred indices to report goodness-of-fit of these models include the Comparative Fit Index (CFI), the Tucker Lewis Index (TLI) (also called the Non-Normed Fit Index (NNFI)) and the Root Mean Square Error of Approximation (RMSEA). According to various experts in this field, a fair to good fit is indicated by CFI- and TLI-values of 0.9 and higher and a RMSEAvalue of 0.07 or lower $[57,58]$. In Table 2 , the mean scores of these values, as calculated over the four measurements in time, are reported. All questionnaires showed a good fit based on the CFI, TLI/NNFI and RMSEA. A lack-of-fit was only found for the 7-item Pearlin Mastery Scale (PMS). Two items performed poorly, violating both the monotonicity and unidimensionality assumptions. During principal components analysis, second factor loadings were remarkably high for these items. The items were therefore omitted, one of which was disregarded in previous research as well because of redundancy [59]. This resulted in the 5-item mastery scale ('PMS-5'), which was used during further analysis, with evidently better performance on all indices, most importantly a decrease of the Root Mean Square Error of Approximation (RMSEA) from 0.106 to 0.078 .

\section{Primary analyses}

For LMM analyses based on continuous logMAR visual acuity data, regression coefficients, standard errors and $p$-values are summarised in Table 3 . In the uncorrected models, visual acuity was associated with significantly lower depression scores $(\beta=0.341, p<0.001)$ and a greater sense of mastery $(\beta=-0.589, p<0.001)$ and selfesteem $(\beta=-0.215, p<0.001)$. No significant association between visual acuity and anxiety was found.

Models were checked for confounding on demographic variables, and gender, age and number of comorbid chronic diseases had a significant influence. Therefore, all models were adjusted for gender, age and comorbid diseases (See Table 3). In the corrected models, $\log$ MAR visual acuity was associated with significantly higher depression scores $(\beta=0.235, p<0.001)$ and a lower sense of mastery $(\beta=-0.477, p<0.001)$ and self-esteem $(\beta=-0.166, p=0.008)$. Still, no significant association between visual acuity and anxiety was found.

Table 2 Goodness-of-fit indices for the used questionnaires

\begin{tabular}{llll}
\hline & CFI & TLI/NNFI & RMSEA \\
\hline Depression (CES-D) & 0.97 & 0.97 & 0.067 \\
Anxiety (HADS-A) & 0.99 & 0.99 & 0.053 \\
Mastery (PMS) & 0.96 & 0.95 & 0.106 \\
Mastery (PMS-5) & 0.99 & 0.98 & 0.078 \\
Self-esteem (RSES) & 1.00 & 1.00 & 0.0148 \\
\hline
\end{tabular}

Center for Epidemiologic Studies - Depression Scale (CES-D), Hospital Anxiety and Depression Scale - Anxiety Subscale (HADS-A), Pearlin Mastery Scale (PMS) and Rosenberg Self-Esteem Scale (RSES) 
Table 3 Linear mixed models (LMMs) on logMAR visual acuity

\begin{tabular}{|c|c|c|c|c|c|c|c|c|c|c|c|c|}
\hline & \multicolumn{6}{|c|}{ Dependent variables } & \multicolumn{6}{|c|}{ Potential mediators } \\
\hline & \multicolumn{3}{|c|}{ Depression (CES-D) } & \multicolumn{3}{|c|}{ Anxiety (HADS-A) } & \multicolumn{3}{|c|}{ Mastery (PMS-5) } & \multicolumn{3}{|c|}{ Self-esteem (RSES) } \\
\hline & $\beta$ & SE & $p$ & $\beta$ & SE & $p$ & $\beta$ & SE & $p$ & $\beta$ & SE & $p$ \\
\hline \multicolumn{13}{|l|}{ Visual Impairment } \\
\hline Crude analysis & 0.341 & 0.059 & 0.000 & 0.082 & 0.057 & 0.147 & -0.589 & 0.066 & 0.000 & -0.215 & 0.062 & 0.000 \\
\hline Adjusted analysis ${ }^{+}$ & 0.235 & 0.060 & 0.000 & 0.032 & 0.058 & 0.579 & -0.477 & 0.067 & 0.000 & -0.166 & 0.063 & 0.008 \\
\hline
\end{tabular}

${ }^{+}$Adjusted for gender, age and number of comorbid chronic disorders

CES-D (Center for Epidemiologic Studies - Depression Scale) [29], HADS-A (Hospital Anxiety and Depression Scale - Anxiety Subscale) [30],

PMS-5 (5-item Pearlin Mastery Scale) [31] and RSES (Rosenberg Self-Esteem Scale) [32]

\section{Mediation analyses}

Since no significant association between visual acuity and anxiety was found, the mediated effect of mastery and self-esteem was only investigated in the association between visual acuity and depression.

With self-esteem included as a potential mediator (see Table 4), the total effect of visual acuity on depression diminished from $\beta=0.341$ to a direct effect of $\beta=0.271$ in the uncorrected model and from $\beta=0.235$ to $\beta=$ 0.164 in the corrected model. This amounts to a mediated percentage of $22.0 \%$ for the uncorrected model and $25.4 \%$ for the corrected model. The direct effect of visual acuity on depression remained statistically significant in the final model.

With mastery included as a potential mediator (see Table 4), the total effect of visual acuity on depression diminished from $\beta=0.341$ to a direct effect of $\beta=0.124$ in the uncorrected model and from $\beta=0.235$ to $\beta=$ 0.047 in the corrected model. This amounts to a mediated percentage of $65 \%$ for the uncorrected model and $79 \%$ for the corrected model. The direct effect of visual acuity on depression lost its statistical significance in the final model.

\section{Discussion}

Visual impairment was found to be associated with depression over time. Previous longitudinal studies reported conflicting results: some found an association between visual impairment and the development of depression [13, 60-65], while others did not [66, 67]. We provide additional evidence based on a large sample and longitudinal follow-up supporting the hypothesis that visual impairment predicts depression. This accentuates the importance of adequate detection of mental health changes in those who develop visual impairment over time. Therefore, screening and monitoring procedures for depression should be a routine part of low vision care.

Still, some individuals with severe vision loss may experience no depressive symptoms, while others with minor vision loss can be severely depressed and symptoms can fluctuate over time [68]. Identification of intrapersonal factors responsible for these variations are therefore essential to understand the impact of visual impairment on mental health and its consequences on offering tailored support. In our study we found that the association of visual impairment and depression is

Table 4 Linear mixed models (LMMs) on the mediation of self-esteem and mastery in the association between visual acuity and depression

\begin{tabular}{|c|c|c|c|c|c|c|c|c|}
\hline & & & \multicolumn{3}{|c|}{ Crude model } & \multicolumn{3}{|c|}{ Adjusted model ${ }^{+}$} \\
\hline & & & $\beta$ & SE & $p$ & $\beta$ & SE & $p$ \\
\hline \multicolumn{9}{|l|}{ Depression } \\
\hline Total effect & c & Visual acuity & 0.341 & 0.059 & 0.000 & 0.235 & 0.060 & 0.000 \\
\hline a-path & $a$ & Visual acuity & -0.215 & 0.062 & 0.001 & -0.166 & 0.063 & 0.008 \\
\hline \multirow[t]{2}{*}{ Direct effect } & $c^{\prime}$ & Visual acuity & 0.271 & 0.060 & 0.000 & 0.164 & 0.061 & 0.007 \\
\hline & $b$ & Self-esteem & -0.355 & 0.0128 & 0.000 & -0.336 & 0.0128 & 0.000 \\
\hline \multicolumn{9}{|l|}{ Depression } \\
\hline Total effect & c & Visual acuity & 0.341 & 0.059 & 0.000 & 0.235 & 0.060 & 0.000 \\
\hline a-path & $a$ & Visual acuity & -0.600 & 0.067 & 0.000 & -0.458 & 0.063 & 0.000 \\
\hline \multirow[t]{2}{*}{ Direct effect } & $c^{\prime}$ & Visual acuity & 0.124 & 0.059 & 0.032 & 0.054 & 0.060 & 0.366 \\
\hline & $b$ & Mastery & -0.388 & 0.013 & 0.000 & -0.366 & 0.013 & 0.000 \\
\hline
\end{tabular}


mediated by loss of self-esteem and loss of mastery, which is supported by recent literature [69, 70]. People with visual impairment often feel a loss of control [3335] and reduced self-esteem [38] in performing activities in everyday life. These intrapersonal factors largely explain the development of depression in this population. By addressing these factors in healthcare, we may be able to approach the imminent problem of depression in patients with visual impairment. In addition, it may help identify those who are at risk of developing depression and to be able to intervene at an earlier stage. Prior studies suggest that offering group-based rational emotive behavioural therapy within low vision service settings may improve self-esteem in people with visual impairment [71], which may in turn reduce depression. Moreover, a self-management program $[72,73]$ and a social competence training [74] offered within low vision services may increase self-efficacy in this population. Self-efficacy, i.e. believing in one's own ability to produce desirable results in a specific area, is related to mastery. People with high self-efficacy about a certain task will most likely have a high sense of mastery. Still, a recent meta-analysis showed that the certainty of evidence on interventions to improve self-efficacy and self-esteem in adults with visual impairment is low with a high risk of bias, high risk of imprecision and inconsistency in results [75]. Therefore, more high quality studies are needed to improve evidence-based care to address mastery and self-esteem in people with visual impairment, and in turn reduce depression.

In apparent contrast to results from previous crosssectional $[10,76]$ and longitudinal studies $[60,77]$, an association between vision loss and anxiety was not found. A recent longitudinal cohort study in older adults $(n=$ 7584) by Frank et al. also found no association between self-reported visual impairment and anxiety [64]. Differences may be explained by the way visual impairment is measured. Vision loss encompasses more than just visual acuity (e.g. visual field defects) and self-reported (subjective) vision loss as a measurement for visual impairment may potentially invite response bias (e.g. recall and social desirability bias) and confounding by personality type [64, 78]. Additional investigations are needed to confirm findings and establish whether a causal association exists.

\section{Strengths and limitations}

The use of longitudinal data from a large general population has augmented this study's value. Most notably, this research has contributed to visual impairment research by unravelling the mediating roles of self-esteem and mastery in the longitudinal association between visual acuity and depression, which has not previously been attempted. In addition, IRT analyses were performed to increase the accuracy of the results based on validated questionnaires. Because of the large and representative sample size and the broad study design, our findings may be generalizable to other community-dwelling populations in high-income countries. However, for countries fundamentally dissimilar to the Netherlands, the strength of the found associations might be different.

Also, visual impairment has a relatively low prevalence in the investigated general population. Moreover, visual acuity is but a partial measure for visual functioning. For example, the integrity of the visual field, high-contrast dependency but also experienced visual disability have not been taken into account. Future studies may attempt to incorporate these aspects to more fully assess visual functioning in relation to mental health. In addition, we were not able to analyse and control for possible confounding on the time of onset of the visual impairment, activities of daily living and hearing impairment, which may have played an additional role in the association between visual acuity and mental health.

\section{Conclusion}

In our longitudinal cohort study $(n=2599)$, better visual acuity was associated with greater sense of mastery and self-esteem, and less depression. The relationship between visual acuity and depression was mediated by selfesteem (25\%) and mastery (79\%). These intrapersonal factors can be addressed in mental health programs to ultimately reduce depression.

\section{Abbreviations}

LASA: Longitudinal Aging Study Amsterdam; IRT: Item Response Theory; PST: Problem-solving treatment; LSN: Living Arrangements and Social Networks; METc: Medical Ethics committee; VAR: Visual acuity rating; logMAR: Logarithm of the Minimal Angle of Resolution; CES-D: Center for Epidemiologic Studies - Depression scale; HADS-A: Hospital Anxiety and Depression Scale - Anxiety subscale; PMS: Pearlin Mastery Scale; RSES: Rosenberg Self-Esteem Scale; LMM: Linear mixed modelling; GRM: Graded Response Model; CFA: Confirmatory Factor Analysis; RMSEA: Root Mean Square Error of Approximation

\section{Acknowledgements \\ The authors wish to thank T.J. Heesterbeek, MD, PhD candidate, for his extensive counsel and input during the course of this research. Also, the authors wish to thank C.F.W. Peeters, PhD, and J.J.M. Rijnhart, PhD candidate, for their expertise and assistance on statistical analysis and interpretation, and H.C. Comijs, PhD, for her insight and advice pertaining to the use and deployment of the LASA study and its collected treasure of data.}

Authors' contributions

IM, HvdA and RvN conceived of the study and its design. GvR, AB and JT advised in the development of the design. IM and HvdA drafted the manuscript, which was revised by the other authors. All authors read and approved the final manuscript.

\section{Funding}

The LASA study is supported by a grant from the Netherlands Ministry of Health, Welfare and Sports, Directorate of Long-Term Care. The sponsors had no role in the design and conduct of the study or in the writing of the manuscript. 


\section{Availability of data and materials}

The datasets used and/or analysed during the current study are available from the corresponding author on reasonable request.

\section{Ethics approval and consent to participate}

Data collection for the LASA study was approved by the Medical Ethics committee (METc) of Amsterdam University Medical Centres, location VUmc, the Netherlands. Respondents provided written informed consent before inclusion. The study has been performed according to the ethical standards of the Declaration of Helsinki (1964) and its later amendments.

\section{Consent for publication}

Not applicable.

\section{Competing interests}

The authors declare that they have no competing interests.

\begin{abstract}
Author details
'Amsterdam UMC, Vrije Universiteit Amsterdam, Ophthalmology, Amsterdam Public Health Research Institute, Amsterdam, The Netherlands. ${ }^{2}$ Elkerliek Hospital, Ophthalmology, Helmond, The Netherlands. ${ }^{3}$ Amsterdam UMC, Vrije Universiteit Amsterdam, Psychiatry, Amsterdam Public Health Research Institute, Amsterdam, The Netherlands. ${ }^{4} \mathrm{GGZ}$ inGeest Specialized Mental Health Care, Research and Innovation, Amsterdam, The Netherlands. ${ }^{5}$ Amsterdam UMC, Vrije Universiteit Amsterdam, Epidemiology and Biostatistics, Amsterdam Public Health Research Institute, Amsterdam, The Netherlands.
\end{abstract}

Received: 9 March 2020 Accepted: 3 September 2020 Published online: 24 September 2020

\section{References}

1. Pascolini D, Mariotti SP. Global estimates of visual impairment: 2010. Br J Ophthalmol. 2012;96(5):614-8.

2. Bourne RRAFS, Braithwaite T, Cicinelli MV, Das A, Jonas JB, et al. Magnitude, temporal trends, and projections of the global prevalence of blindness and distance and near vision impairment: a systematic review and meta-analysis. Lancet Glob Health. 2017;5(9):10.

3. Abubakar II, Tillmann T, Banerjee A. Global, regional, and national age-sex specific all-cause and cause-specific mortality for 240 causes of death, 19902013: a systematic analysis for the Global Burden of Disease Study 2013. Lancet. 2015;385(9963):117-71.

4. Keunen JE, Verezen CA, Imhof SM, van Rens GH, Asselbergs MB, Limburg JJ. Increase in the demand for eye-care services in the Netherlands 2010-2020. Ned Tijdschr Geneeskd. 2011;155(41):A3461.

5. Steel Z, Marnane C, Iranpour C, Chey T, Jackson JW, Patel V, et al. The global prevalence of common mental disorders: a systematic review and metaanalysis 1980-2013. Int J Epidemiol. 2014:43(2):476-93.

6. Blazer DG. Depression in late life: review and commentary. J Gerontol A Biol Sci Med Sci. 2003;58(3):249-65.

7. Lotery AXX, Zlatava G, Loftus J. Burden of illness, visual impairment and health resource utilisation of patients with neovascular age-related macular degeneration: results from the UK cohort of a five-country cross-sectional study. Br J Ophthalmol. 2007;91(10):1303-7.

8. McCusker S, Koola MM. Association of ophthalmologic disorders and depression in the elderly: a review of the literature. Prim Care Companion CNS Disord. 2015;17(4). https://doi.org/10.4088/PCC.14r01731.

9. Ribeiro MV, Hasten-Reiter Junior HN, Ribeiro EA, Juca MJ, Barbosa FT, SousaRodrigues CF. Association between visual impairment and depression in the elderly: a systematic review. Arq Bras Oftalmol. 2015;78(3):197-201.

10. van der $\mathrm{Aa} \mathrm{HPACH}$, Penninx BWJH, van Rens GHMB, van Nispen RMA. Major depressive and anxiety disorders in visually impaired older adults. Invest Ophthalmol Vis Sci. 2015;56(2):849-54.

11. van Nispen RM, Vreeken HL, Comijs HC, Deeg DJ, van Rens GH. Role of vision loss, functional limitations and the supporting network in depression in a general population. Acta Ophthalmol. 2016:94(1):76-82

12. Cosh S, Carriere I, Nael V, Tzourio C, Delcourt C, Helmer C. The association of vision loss and dimensions of depression over 12 years in older adults: findings from the three City study. J Affect Disord. 2019;243:477-84.

13. Hong $T$, Mitchell P, Burlutsky G, Gopinath B, Liew G, Wang JJ. Visual impairment and depressive symptoms in an older Australian cohort: longitudinal findings from the Blue Mountains eye study. Br J Ophthalmol. 2015;99(8):1017-21.

14. Kempen Gl, Zijlstra GA. Clinically relevant symptoms of anxiety and depression in low-vision community-living older adults. Am J Geriatr Psychiatry. 2014;22(3):309-13.

15. Cimarolli VR, Casten RJ, Rovner BW, Heyl V, Sorensen S, Horowitz A. Anxiety and depression in patients with advanced macular degeneration: current perspectives. Clin Ophthalmol. 2016;10:55-63.

16. Casten R, Rovner BW, Leiby BE, Tasman W. Depression despite anti-vascular endothelial growth factor treatment of age-related macular degeneration. Arch Ophthalmol. 2010;128(4):506-8.

17. Hayman KJ, Kerse NM, La Grow SJ, Wouldes T, Robertson MC, Campbell AJ. Depression in older people: visual impairment and subjective ratings of health. Optom Vis Sci. 2007:84(11):1024-30.

18. Hirai FE, Tielsch JM, Klein BE, Klein R. Relationship between retinopathy severity, visual impairment and depression in persons with long-term type 1 diabetes. Ophthalmic Epidemiol. 2012:19:196-203.

19. van der Aa HP, Xie J, Rees G, Fenwick E, Holloway EE, van Rens GH, et al. Validated prediction model of depression in visually impaired older adults. Ophthalmology. 2016;123(5):1164-6.

20. Brody BL, Roch-Levecq AC, Kaplan RM, Moutier CY, Brown SI. Age-related macular degeneration: self-management and reduction of depressive symptoms in a randomized, controlled study. J Am Geriatr Soc. 2006;54(10): 1557-62.

21. Kurtović A, Ivančić H. Predictors of depression and life satisfaction in visually impaired people. Disabil Rehabil. 2019;41(9):1012-23.

22. Sturrock BA, Xie J, Holloway EE, Lamoureux EL, Keeffe JE, Fenwick EK, et al. The influence of coping on vision-related quality of life in patients with low vision: a prospective longitudinal study. Invest Ophthalmol Vis Sci. 2015; 56(4):2416-22.

23. Nyman SR, Dibb B, Victor CR, Gosney MA. Emotional well-being and adjustment to vision loss in later life: a meta-synthesis of qualitative studies. Disabil Rehabil. 2012;34(12):971-81.

24. Senra $H$, Barbosa F, Ferreira $P$, Vieira $C R$, Perrin $P B$, Rogers $H$, et al. Psychologic adjustment to irreversible vision loss in adults: a systematic review. Ophthalmology. 2015;122(4):851-61.

25. McKinzie C, Reinhardt J, Benn D. Adaptation to chronic vision impairment. Res Aging. 2007:29:144-62

26. Rees G, Xie J, Holloway EE, Sturrock BA, Fenwick EK, Keeffe JE, et al. Identifying distinct risk factors for vision-specific distress and depressive symptoms in people with vision impairment. Invest Ophthalmol Vis Sci. 2013;54(12):7431-8.

27. Rovner BW, Casten RJ, Hegel MT, Massof RW, Leiby BE, Ho AC, et al. Low vision depression prevention trial in age-related macular degeneration: a randomized clinical trial. Ophthalmology. 2014;121(11):2204-11.

28. Schilling OK, Wahl HW, Boerner K, Horowitz A, Reinhardt JP, Cimarolli VR, et al. Developmental regulation with progressive vision loss: use of control strategies and affective well-being. Dev Psychol. 2016;52(4):679-94.

29. Sturrock BA, Xie J, Holloway EE, Hegel M, Casten R, Mellor D, et al. Illness cognitions and coping self-efficacy in depression among persons with low vision. Invest Ophthalmol Vis Sci. 2016;57(7):3032-8.

30. Pearlin LI, Schooler C. The structure of coping. J Health Soc Behav. 1978; 19(1):2-21.

31. Steunenberg B, Beekman AT, Deeg DJ, Bremmer MA, Kerkhof AJ. Mastery and neuroticism predict recovery of depression in later life. Am J Geriatr Psychiatry. 2007;15(3):234-42.

32. Infurna FJ, Mayer A. The effects of constraints and mastery on mental and physical health: conceptual and methodological considerations. Psychol Aging. 2015;30(2):432-48.

33. Cimarolli VR, Boerner K, Reinhardt JP, Horowitz A, Wahl HW, Schilling O, et al. A population study of correlates of social participation in older adults with age-related vision loss. Clin Rehabil. 2016;31(1):115-25.

34. Papadopoulos K. The impact of individual characteristics in self-esteem and locus of control of young adults with visual impairments. Res Dev Disabil. 2014;35(3):671-5.

35. Papadopoulos K, Montgomery AJ, Chronopoulou E. The impact of visual impairments in self-esteem and locus of control. Res Dev Disabil. 2013; 34(12):4565-70.

36. Bjorklof GH, Engedal K, Selbaek G, Maia DB, Coutinho ES, Helvik AS. Locus of control and coping strategies in older persons with and without depression. Aging Ment Health. 2016;20(8):831-9. 
37. Alexander FE. Self-concepts of children with visual impairments. Review. 1996;28(1):35-43.

38. Sowislo JF, Orth U. Does low self-esteem predict depression and anxiety? A meta-analysis of longitudinal studies. Psychol Bull. 2013;139(1):213-40.

39. Huisman M, Poppelaars J, van der Horst M, Beekman AT, Brug J, van Tilburg TG, et al. Cohort profile: the longitudinal aging study Amsterdam. Int J Epidemiol. 2011;40(4):868-76.

40. Knipscheer CP, Dykstra PA, van Tilburg TG, de Jong-Gierveld J. Living arrangements and social networks of elders. A selection of findings from a NESTOR-study. Tijdschr Gerontol Geriatr. 1998;29(3):110-9.

41. Beekman AT, Deeg DJ, van Tilburg T, Smit JH, Hooijer C, van Tilburg W. Major and minor depression in later life: a study of prevalence and risk factors. J Affect Disord. 1995;36(1-2):65-75.

42. Beekman AT, Deeg DJ, Braam AW, Smit JH, Van Tilburg W. Consequences of major and minor depression in later life: a study of disability, well-being and service utilization. Psychol Med. 1997;27(6):1397-409.

43. Beekman AT, Deeg DJ, Van Limbeek J, Braam AW, De Vries MZ, Van Tilburg W. Criterion validity of the Center for Epidemiologic Studies Depression scale (CES-D): results from a community-based sample of older subjects in the Netherlands. Psychol Med. 1997;27(1):231-5.

44. Grimes DA, Schulz KF. Bias and causal associations in observational research. Lancet. 2002;359(9302):248-52.

45. Colenbrander A. Measuring vision and vision loss. In: Duane TD, Tasman, W, Edward A, editor. Duane's Clinical Ophthalmology. 5. San Francisco: Lippincott Williams \& Wilkins; 2001.

46. Elliott DB. The good (logMAR), the bad (Snellen) and the ugly (BCVA, number of letters read) of visual acuity measurement. Ophthalmic Physiol Opt. 2016;36(4):355-8.

47. Radloff LS. The CES-D scale: a self-report depression scale for research in the general population. Appl Psychol Meas. 1977;1(3):385-401.

48. Zigmond AS, Snaith RP. The hospital anxiety and depression scale. Acta Psychiatr Scand. 1983;67(6):361-70.

49. Rosenberg, M. Society and the adolescent self-image. Princeton: NJ: Princeton University Press; 1965.

50. Subhi Y, Sørensen T. Neovascular age-related macular degeneration in the very old ( $\geq 90$ years): epidemiology, adherence to treatment, and comparison of efficacy. J Ophthalmol. 2017;2017:7194927.

51. Yang FM, Kao ST. Item response theory for measurement validity. Shanghai Arch Psychiatry. 2014;26(3):171-7.

52. Molenaar D, Tuerlinckx F, van der Maas HLJ. Fitting diffusion item response theory models for responses and response times using the $R$ package diffIRT. J Stat Softw. 2015;66(4). https://www.jstatsoft.org.

53. Rosenbaum PR. Testing the conditional independence and monotonicity assumptions of item response theory. Psychometrika. 1984:49(3):425-35.

54. van der Ark LA. Mokken scale analysis in R. J Stat Softw. 2007;20(11). https:// www.jstatsoft.org.

55. Ibrahim JG, Molenberghs G. Missing data methods in longitudinal studies: a review. Test (Madr). 2009;18(1):1-43.

56. Deeg DJ, van Tilburg T, Smit JH, de Leeuw ED. Attrition in the longitudinal aging study Amsterdam. The effect of differential inclusion in side studies. J Clin Epidemiol. 2002;55(4):319-28.

57. Steiger $\mathrm{JH}$. Understanding the limitations of global fit assessment in structural equation modeling. Personal Individ Differ. 2007;42(5):893-8.

58. BMW MCRC, Sugawara HM. Power analysis and determination of sample size for covariance structure modeling. Psychol Methods. 1996;1(2):130-49.

59. Statistics NLSBoL. Pearlin mastery scale IRT item parameter estimates, scores and standard errors with custom weighted Z-scores and percentile ranks Washington, DC. 2016 [updated February 2, 2016. Available from: https://www. nlsinfo.org/sites/nlsinfo.org/files/attachments/160212/Pearlin\%20Mastery\%2 OScale\%20-\%20Description\%20of\%20Creation\%20Procedures.pdf.

60. Heesterbeek TJ, van der Aa HPA, van Rens G, Twisk JWR, van Nispen RMA The incidence and predictors of depressive and anxiety symptoms in older adults with vision impairment: a longitudinal prospective cohort study. Ophthalmic Physiol Opt. 2017;37(4):385-98.

61. Tournier M, Moride Y, Ducruet T, Moshyk A, Rochon S. Depression and mortality in the visually-impaired, community-dwelling, elderly population of Quebec. Acta Ophthalmol. 2008:86(2):196-201.

62. Harris T, Cook DG, Victor C, DeWilde S, Beighton C. Onset and persistence of depression in older people--results from a 2-year community follow-up study. Age Ageing. 2006;35(1):25-32.
63. Zheng DD, Bokman CL, Lam BL, Christ SL, Swenor BK, West SK, et al. Longitudinal relationships between visual acuity and severe depressive symptoms in older adults: the Salisbury Eye Evaluation study. Aging Ment Health. 2015;20(3):295-302.

64. Frank CR, Xiang X, Stagg BC, Ehrlich JR. Longitudinal associations of selfreported vision impairment with symptoms of anxiety and depression among older adults in the United States. Aging Ment Health. 2019;137(7): 793-800.

65. Choi HG, Lee MJ, Lee SM. Visual impairment and risk of depression: a longitudinal follow-up study using a national sample cohort. Sci Rep. 2018; 8(1):2083.

66. Prince MJ, Harwood RH, Thomas A, Mann AH. A prospective populationbased cohort study of the effects of disablement and social milieu on the onset and maintenance of late-life depression. The gospel oak project VII. Psychol Med. 1998;28(2):337-50.

67. Forsell Y. Predictors for depression, anxiety and psychotic symptoms in a very elderly population: data from a 3-year follow-up study. Soc Psychiatry Psychiatr Epidemiol. 2000;35(6):259-63.

68. Eaton WW, Shao H, Nestadt G, Lee HB, Bienvenu OJ, Zandi P. Populationbased study of first onset and chronicity in major depressive disorder. Arch Gen Psychiatry. 2008;65(5):513-20.

69. Assari S. Association between self-esteem and depressive symptoms is stronger among black than white older adults. J Racial Ethn Health Disparities. 2017:4:687-95.

70. Bennetter KE, Clench-Aas J, Raanaas RK. Sense of mastery as mediator buffering psychological distress among people with diabetes. J Diabetes Complicat. 2016;30(5):839-44.

71. Mozaffar Jalali MD, Moussavi MS, Amin Yazdi SA, Salehi FJ. Effectiveness of rational emotive behavior therapy on psychological well-being of people with late blindness. J Rational Emotive Cogn Behav Ther. 2014;32(4):23-47.

72. Brody BL, Williams RA, Thomas RG, Kaplan RM, Chu RM, Brown SI. Agerelated macular degeneration: a randomized clinical trial of a selfmanagement intervention. Ann Behav Med. 1999:21(4):322-9.

73. Brody BL, Roch-Levecq AC, Gamst AC, Maclean K, Kaplan RM, Brown SI. Selfmanagement of age-related macular degeneration and quality of life: a randomized controlled trial. Arch Ophthalmol. 2002;120(11):1477-83.

74. Rumrill PD. Effects of a social competence training program on accommodation request activity, situational self-efficacy, and Americans with disabilities act knowledge among employed people with visual impairments and blindness. J Vocational Rehabil. 1999;12(1):25-31.

75. van Munster E, van der Aa HPA, Verstraten P, Van Nispen RMA. Identifying depression and anxiety in adults with visual impairment: the patient's perspective (unpublished results). 2020

76. Evans JR, Fletcher AE, Wormald RP. Depression and anxiety in visually impaired older people. Ophthalmology. 2007;114(2):283-8.

77. Cosh S, von Hanno T, Helmer C, Bertelsen G, Delcourt C, Schirmer H, et al. The association amongst visual, hearing, and dual sensory loss with depression and anxiety over 6 years: the Tromso study. Int J Geriatr Psychiatry. 2018;33(4):598-605.

78. Jampel HD, Frick KD, Janz NK, Wren PA, Musch DC, Rimal $R$, et al. Depression and mood indicators in newly diagnosed glaucoma patients. Am J Ophthalmol. 2007;144(2):238-44 e1

\section{Publisher's Note}

Springer Nature remains neutral with regard to jurisdictional claims in published maps and institutional affiliations.

Ready to submit your research? Choose BMC and benefit from:

- fast, convenient online submission

- thorough peer review by experienced researchers in your field

- rapid publication on acceptance

- support for research data, including large and complex data types

- gold Open Access which fosters wider collaboration and increased citations

- maximum visibility for your research: over $100 \mathrm{M}$ website views per year

At BMC, research is always in progress.

Learn more biomedcentral.com/submission 